\title{
Contemporary Trauma Theory and Trauma-Informed Care in Substance Use Disorders: A Conceptual Model for Integrating Coping and Resilience
}

\section{Revital Goodman}

\begin{abstract}
National data of children's exposure to traumatic experiences are alarming. Research asserts the interconnectedness between experiencing childhood trauma $(C T)$ or adverse childhood experiences (ACE) and developing substance use disorders (SUDs) in later adulthood. Trauma definition and contemporary trauma theory (CTT) provide the foundation for trauma informed care (TIC) in social work practice with co-occurring trauma and SUDs. TIC re-conceptualizes SUDs as a mechanism to cope with the effects of trauma. Coping and resilience are relevant factors to the ramifications of CT on SUDs, and are the manifestation of key TIC principles. Integrating TIC practices aimed at enhancing coping and resilience into treatment for co-occurring trauma and SUDs is needed in order to negate the devastating impact of trauma and propel recovery. Conclusions and implications to social work practice are discussed.
\end{abstract}

Keywords: Childhood-trauma; ACE; TIC; substance use disorders; coping; resilience

National data of children's exposure to traumatic experiences are alarming. According to the National Center for Mental Health Promotion and Youth Violence Prevention (2012), $26 \%$ of children in the United States will witness or experience a traumatic event before they turn four, with four of every 10 children reporting experiencing a physical assault during the past year (Finkelhor, Turner, Shattuck, \& Hamby, 2013). Other reports indicate that more than $60 \%$ of youth age 17 and younger have been exposed to crime, violence, and abuse either directly or indirectly (Finkelhor, Turner, Shattuck, Hamby, \& Kracke, 2015). The high prevalence of substance use disorders (SUDs) constitutes a growing problem in the United States, with an overwhelming number of persons challenged with this cluster of disorders (U.S. Department of Health and Human Services, Office of the Surgeon General, 2016). Research asserts the interconnectedness between experiencing childhood trauma (CT) or adverse childhood experiences (ACE) and the subsequent underlying mechanisms that contribute to the development of SUDs and to recovery from drug and alcohol addiction (Driessen, et al., 2008; Dube, et al., 2003; Elwyn \& Smith, 2013; Felitti, et al., 1998; Harris, Lieberman, \& Marans, 2007; Levenson, 2016; Levenson \& Grady, 2016). Compelling associations between CT and SUDs define a growing need for social workers practicing in the field of SUDs to frame clinical practices through the lens of trauma-informed care (TIC; Levenson, 2015). Social workers practicing in the field of addiction need to thoroughly assess past trauma experiences in order to have a better understanding of clients' presentation and symptoms. Through the lens of TIC, clients' poor clinical presentations and maladaptive functioning are perceived as the manifestation of unresolved trauma and impaired self-regulatory skills; higher dysfunction and disruptive clinical presentations suggest higher probability for a complex history of unresolved trauma. Discounting the role of trauma within this clinical population may lead to inaccurate diagnoses and to subsequent inaccurate treatment, which may result in a

Revital Goodman, PhD, LCSW, is a Clinical Practitioner and an Adjunct Professor at Barry University School of Social Work, Miami Shores, FL 33161

Copyright $\odot 2017$ Author, Vol. 18 No. 1 (Spring 2017), 186-201, DOI: 10.18060/21312

(cc) BY

This work is licensed under a Creative Commons Attribution 4.0 International License. 
higher percentage of treatment attrition or relapse. In order to better understand and practice TIC for this clinical population, it is essential to integrate recent findings from the fields of trauma and SUDs with a comprehensive theoretical foundation. Finally, the current knowledge about the curative influence of coping and resilience on co-occurring CT and SUDs provides social workers with tangible tools to improve treatment and enhance recovery.

\section{Theoretical Foundation for Trauma Informed Care: Trauma, and Contemporary Trauma Theory}

Trauma has been perceived and defined in different ways over the years, contingent on the development of knowledge and the understanding of the impact of traumatic experiences on the individual, family, community, and society (van der Kolk, 2014). In recent decades, the definition of trauma has been consistently inclusive of the following elements: (1) an identified event or series of events, that is (2) experienced by the individual as physically or emotionally harmful, threatening, or overwhelming, and (3) has lasting and holistic effects on the individual's functioning (Herman, 1992; Laplanche \& Pontalis, 1973; Ringel \& Brandell, 2012; Substance Abuse and Mental Health Services Administration (SAMHSA), 2012; van der Kolk, 2014). CT "overwhelms the ordinary human adaptation to life" (Herman, 1992, p. 33) and the person's sense of control, which may lead to maladaptive internalization of the event. Such maladaptive internalization may result in disturbance to bio-psychosocial functioning, healthy development, and brain performance in regions that are related to emotions, behavior, and executive functioning (Lizeretti, Extremera, \& Rodriguez, 2012; SAMHSA, 2012; Suleiman, 2008; van der Kolk, 2014). The development of contemporary trauma theory (CTT) represents a paradigm shift in how social workers perceive and treat survivors of trauma. The new trauma-based paradigm, refrains from viewing survivors' poor functioning as resulting from sickness, weakness, or deficiencies in moral character, and reframes viewing survivors as psychologically and physically injured, and instead, in need of healing and help (Bloom \& Farragher, 2011; Salovey \& Sluyter, 1997; van der Kolk, 2014; Williams, 2006). CTT provides a theoretical framework for understanding the impact trauma has on a person's functioning, and is based on the following central properties:

a) Dissociation. Dissociation in trauma "entails a division of an individual's personality, that is, of the dynamic, bio-psychosocial system as a whole that determines his or her characteristic mental and behavioral actions" (Nijenhuis \& van der Hart, 2011, p. 418). Dissociation is the main defense mechanism used by a victim to negotiate and tolerate the horrific traumatic experience (Herman, 1992; Siegal, 1999; Suleiman, 2008; van der Kolk, 2014; Williams, 2006).

b) Attachment. CT impacts a person's ability to develop healthful interpersonal relationships and to establish trust, leading to impairment in the abilities to form secured attachment with others and to interruptions in interpersonal relationships (O’Connor \& Elklit, 2008; Siegal, 2010; Tarren-Sweeney, 2013).

c) Reenactment. A phenomenon in which victims seek relationships and display behaviors that reenact the original traumatic event (Courtois \& Ford, 2016). 
Reenactment elicits an intense emotional state that releases tension or anxiety and provides the person with a sense of control and connectedness (van der Kolk, 2014).

d) Long-term effect on later adulthood. Unresolved CT may have devastating effects on functioning in adulthood (Becker-Blease \& Freyd, 2005). Trauma that is experienced by a child inhibits appropriate development and predisposes the child to negative recurrence later in life, including comorbidity in physical and mental health problems (Ross, 2000; Williams, 2006). In addition, CT diminishes the basic sense of self and leads to destruction of intrapersonal and interpersonal capacities (Courtois, 2008; Herman, 1992; Lewis, 2012; Ringel \& Brandell, 2012; Salovey \& Sluyter, 1997; Shapiro, 2012; van der Kolk, 2014; Williams, 2006).

e) Impairment in emotional capacities. Emotional numbing and the break down of the self-regulatory system are direct impacts of trauma on the brain and on the adaptive functioning of the limbic system, the part of the brain that supports a variety of functions, including the emotional life (Badenoch, 2008; Salovey \& Sluyter, 1997; Siegal, 1999; van der Kolk, 2014). Traumatic events, and especially prolonged exposure to trauma, which is typical in childhood abuse or neglect, diminish the sense of baseline state of both emotional and physical calm or comfort, resulting in hyper-arousal symptoms that include hypervigilant, anxiety, agitation, night terror, and somatization (Herman, 1992; Siegal, 1999; Shapiro, 2010; Van der Kolk, 2014; Van der Kolk, McFarlane, \& Weisaeth, 2006; Williams, 2006). Victims of CT display compromised ability to regulate their moods and their emotional responses as adults, including the ability to identify emotions in self and others, to understand emotions, and to self-regulate, which may lead to dissociation and dissociative identity disorder in extreme cases of abuse (Levendosky \& Buttenheim, 2010; Mészáros, 2010; Salovey \& Sluyter, 1997; Schutte, Malouff, \& Hine, 2011; Shapiro, 2010).

CTT provides a conceptual foundation for understanding the bio-psychosocial impact of trauma on children and adults. Given the devastating impact CT has on brain functioning and on adequate development of social and emotional skills, the correlation between CT and SUDs is prescient.

\section{The Link Between Substance Use Disorders and Childhood Trauma}

Studies validate the deleterious effects of accumulative CT or ACE on future life outcomes, including mental and physical health, social problems, sexually offensive behaviors, and death (Felitti, et al., 1998; Heffernan et al., 2000; Jung, Herrenkohl, Klika, Olivia-Lee, \& Brown, 2014; Levenson, 2016). Research in the area of mental health indicates high correlations between ACE or CT and SUDs (Banducci, Hoffman, Lejuez, \& Koenen, 2014a). These correlations signify an essential need to integrate TIC into treatment for SUDs. 
Research provides robust correlation between trauma and substance abuse, ACE and serious problems with drug use, and trauma as an independent risk factor for drug or alcohol relapse in substance-abusing populations (Dube et al., 2003; Elwyn \& Smith, 2013; Felitti, et al., 1998; Harris, Lieberman, \& Marans, 2007; Levenson, 2016; Levenson \& Grady, 2016; Torchalla, Nosen, Rostam, \& Allen, 2012). Child maltreatment refers to dominant and/or persistent environmental stressors that hinder the development of personality and may lead to increased psychopathology (Handley, Rogosch, Guild, \& Cicchetti, 2015; Oshri \& Rogosch, 2013). Exposure to chronic victimization results in more global dysfunction, added distress, and vulnerability (Turner, Finkelhor, \& Ormrod, 2010) and is linked to increased risk for substance abuse problems in adulthood (Driessen, et al., 2008; Elwyn \& Smith, 2013). Felitti et al. (1998) found that ACE account for one-half to two-thirds of increased problems with drug use among over 17,000 adult patients of the Kaiser Permanente Health System. The writers identified strong positive correlations between the ACE score and initiation of illicit drug use problems and drug addiction. Similarly, later studies linked exposure to violence in childhood with a greater risk for alcohol and drug abuse in adulthood (Harris, et al., 2007; Jung et al., 2014; van der Kolk, 2014). CT was identified as an independent risk factor for drug or alcohol relapse in a sample recruited from a substance-abusing population (Driessen et al., 2008). Finally, while CT adversely affects both men and women, studies indicate higher rates of childhood sexual abuse among women diagnosed with SUDs compared to childhood physical abuse among men diagnosed with SUDs. Data suggest CT rates between $60 \%-75 \%$ of women enrolled in SUDs treatment (Keyser-Marcus, et al., 2015).

\section{Consequences of Co-Occurring Trauma and SUDs}

Research highlights severely adverse consequences of co-occurring trauma and SUDs. Significant correlations exist between CT and SUDs and deleterious patterns of substance abuse comorbidity, and higher rates of all psychiatric disorders, including mood disorders, anxiety disorders, psychotic symptoms, and personality disorders (Bombardier et al., 2004; Brucker, 2007; Dickey, Azeni, Weiss, \& Sederer, 2000; Ross, 2000). Persons with a CT history and SUDs diagnosis report high frequency of suicidal thoughts and suicide attempts (Keyser-Marcus, et al., 2015). There is recent evidence that type of childhood abuse correlates with maladaptive emotional and behavioral patterns among adults diagnosed with SUDs. Childhood sexual abuse is linked with risky sexual behaviors in adulthood, childhood physical abuse with aggressive behaviors, and childhood emotional abuse with emotion dysregulation (Banducci, Hoffman, Lejuez, \& Koenen, 2014b). Finally, cooccurring CT and SUDs are correlated to myriad physical health problems, sexually transmitted diseases, homelessness, decreased psychosocial functioning, poor well-being, and an overall reduction in quality of life (Levenson, 2015; Wu, Schairer, Dellor, \& Grella, 2010). 


\section{The Curative Roles of Coping and Resilience}

Research findings indicate that coping and resilience are curative factors that play an important role in mitigating the impact of CT on later SUDs (Kuper, Gallop, \& Greenfield, 2010; Schneider, Lyons, \& Khazon, 2013; Weiland, et al., 2012). Coping is defined as a range of skills and strategies employed by the individual in counteracting the negative impact of stressful or challenging life experiences (Valtonen, Sogren, \& CameronPadmore, 2006). Coping includes a wide range of behavioral and cognitive activities that play an important role in functioning, adaptation, and general quality of life (Toker, Tiryaki, Ozçürümez, \& Iskender, 2011). Resilience is defined as the capacity to spring back and successfully adapt in the face of adversity (Henderson \& Milstein, 1996). The resilient person is able to develop adaptive functioning and competences despite exposure to severe stress (Henderson \& Milstein, 1996). In the context of drug addiction, resilience is defined as the person's ability to tolerate, adapt, or overcome crises (Beauvais \& Oetting, 1999).

Coping style is a vital protective factor associated with substance use abstinence and maintaining sobriety (Kuper et al., 2010). Advanced coping is associated with decreased internalized stigma and with increased adaptation among persons diagnosed with SUDs (Chou, Robb, Clay, \& Chronister, 2013; Valtonen, et al., 2006). Poor coping styles are associated with more severe and detrimental substance use pathways and relapse (Franken, Hendriks, Haffmans, \& van der Meer, 2003; Lyvers \& Edward, 2008). Furthermore, nonadaptive coping is prevalent among clinical samples of adults with a history of CT and cooccurring SUDs. Findings indicate CT significantly compromises overall coping capacities; those already compromised coping capacities are further weakened by harmful patterns of alcohol and drug abuse (Lyvers \& Edward, 2008; Smyth \& Wiechelt, 2005; Toker, et al., 2011). Recent conceptualizations of coping highlight the interconnectedness between coping and emotional regulation skills and impulse control, and suggest that better coping skills are contingent on sophisticated emotional capacities (Erozkan, 2013; Mikolajczak, Nelis, Hansenne, \& Quoidbach, 2008; Saklofske, Austin, Galloway, \& Davidson, 2007). Emotional capacities and advanced coping are significantly and positively correlated, with the ability to regulate emotions being a reliable predictor of the ability to employ a wide range of coping strategies to negotiate stressors (Downey, Johnston, Hansen, Birney, \& Stough, 2010; Mikolajczak, et al., 2008; Perera \& DiGiacomo, 2015; Zeidner, Kloda, \& Matthews, 2013).

Research affirms the central role of resilience in CT and SUDs. Higher resilience is related to lower levels of substance use, fewer alcohol problems, and a delayed onset of substance abuse (Weiland et al., 2012). Similarly, enhanced resilience plays a significant protective role in successful recovery from SUDs (Roberts, Galassi, McDonald, \& Sachs, 2002). Researchers provide compelling evidence in support of the association between emotional capacities and resilience, and of resilience as a mediating factor among advanced emotional capacities, affect balance, and well-being (Armstrong, Galligan, \& Critchley, 2011; Liu, Wang, \& Lu, 2013; Zeidner, Matthews \& Roberts, 2012). Advanced emotional capacities relate to stress resilience (Schneider et al., 2013) and demonstrate strong relationships with resilience factors among clinical samples of young adults with cooccurring CT and SUDs (Montgomery et al., 2008). As such, enhanced resilience is tied to enhanced abilities to tolerate stress and to regulate emotions despite adversities, reducing 
the person's need to self-medicate with substances.

\section{Contemporary Trauma Theory and Trauma-Informed Care: An Emerging Conceptual and Integrative Model for Enhancing Coping and Resilience (CORE)}

Building on the existing literature pertaining the high rates of co-occurring CT and SUDs among adults, research asserts both the need and the effectiveness of adding TIC and trauma-focused strategies into standard SUDs treatment (Back et al., 2014; Covington, 2008; van Dam, Ehring, Vedel, \& Emmelkamp, 2013; Farrugia et al., 2011; Torchalla, et al., 2012). The National Center for Trauma Informed Care (SAMHSA, 2015) published six key guiding principles that inform the spirit and the application of working with trauma survivors. These principles are: (1) safety; (2) trustworthiness and transparency; (3) peer support; (4) collaboration and mutuality; (5) empowerment, voice and choice; and (6) cultural, historical, and gender issues. These six principles reflect and define a resiliencebased approach to enhanced coping. These principles correspond with empirical research that asserts the curative roles of resilience and coping to the ramifications of CT on SUDs. As such, it is postulated that coping and resilience are relevant and essential components that need to be integrated into a TIC model for the treatment of co-occurring trauma and SUDs. Furthermore, it is suggested that an integrative and comprehensive model of TIC to SUDs needs to encompass scientific research, theory, and practice. The research component consists of recognition of the prevalence of childhood trauma, familiarity with the existing scientific correlations between CT and the development of SUDs, and the integration of findings related to the curative roles of coping and resilience. The theoretical component incorporates a clear definition of trauma and a comprehensive understanding of the five tenets of CTT. The theoretical component further illustrates a realistic expectation of clinical presentations that are based on CTT, and provides clinicians with an enhanced understanding of clients' symptomology. Finally, the practical component guides clinicians to proactively apply the key principles of TIC as defined by SAMHSA (2015), in order to originate a superior therapeutic environment and to deliberately create opportunities for clients to enhance coping and resilience within treatment for SUDs. 
Figure 1. Contemporary Trauma Theory and Trauma-Informed Care: An Emerging Conceptual and Integrative Model for Enhancing Coping and Resilience (CORE).

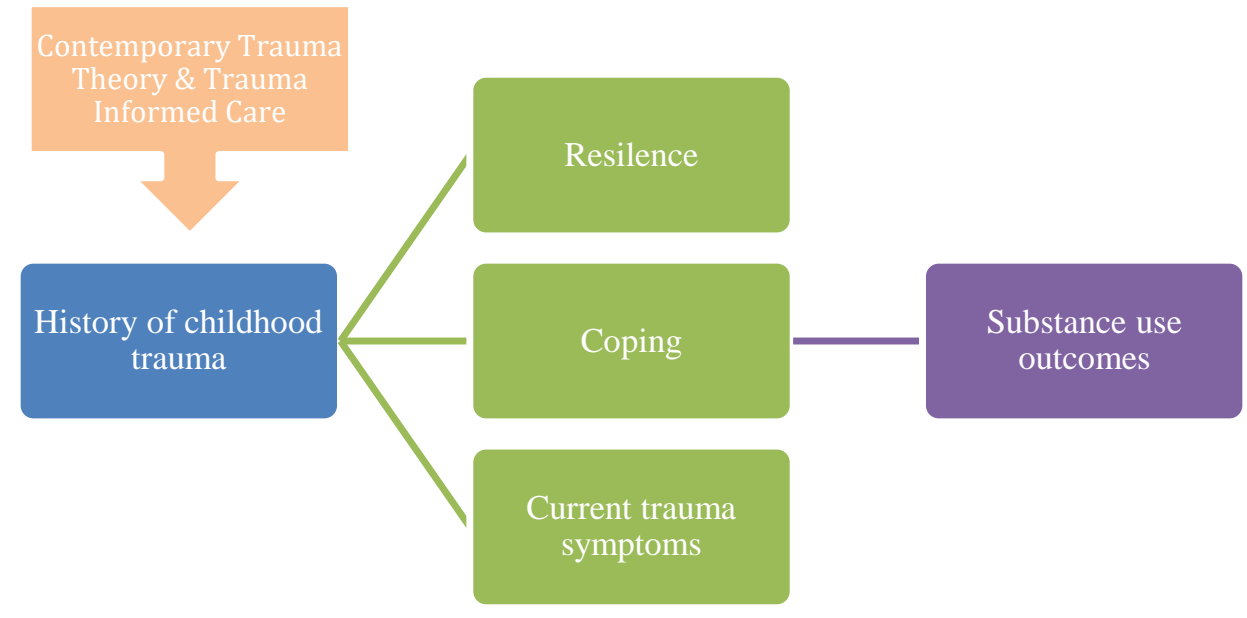

Figure 1. CORE Model summary: This emerging integrative CORE model for treating SUDs incorporates scientific findings of the positive correlations between CT and SUDs, the negative correlations between CT coping and resilience, and of the curative role of coping and resilience in recovery from SUDs. CTT and TIC are the overarching frameworks of the model. CTT provides the framework for understanding clinical presentations and symptomology. TIC defines guiding principles for delivery of services in a manner that recognizes the impact of trauma history and actively seeks to avoid retraumatization. The CORE model suggests viewing SUDs through the lens of childhood trauma history and CTT as well as through the application of TIC principles; these clinical components will directly impact resilience, coping and current trauma symptoms in order to enhance substance use recovery. Childhood trauma is placed outside the direct impact of the intervention in that it provides the lens of treatment needed, and has an impact on current symptoms, yet is not directly impacted by the treatment since the childhood trauma has already happened and cannot be changed.

A trauma-informed approach views presenting problems and symptomology as a maladaptive coping with unresolved traumatic experiences (Levenson, 2014). From a neurobiological perspective, CT and childhood maltreatment -- including the types of trauma or maltreatment, the developmental timing in which the events occurred, and the degree of chronicity -- have an adverse impact on brain structure and development, and on the brain's functioning specifically in regions responsible for impulse control, executive functioning skills, and emotion-focused tasks (Cowell, Cicchetti, Rogosch, \& Toth, 2015; Toth, Gravener-Davis, Guild, \& Cicchetti, 2013). While TIC does not necessarily mean directly addressing trauma (Brown, Baker, \& Wilcox, 2012), it does signify the need to conceptualize the person's presentation through the lens of trauma and CTT. TIC in the context of SUDs views drug and alcohol abuse as a tool to self-medicate and negotiate capacities impeded by unresolved trauma (Khantzian \& Albanse, 2008). The application of TIC to SUDs treatment refrains from viewing the person as deficient in moral character or as lacking motivation, and re-frames the person's presentation as resulting from 
unresolved psychological trauma. The application of TIC into treatment for SUDs promotes viewing the person as lacking a basic sense of safety and as challenged with his or her abilities to display adaptive functioning and employ accurate judgment, especially in emotionally charged situations. Drug and alcohol abuse is perceived as the person's attempt to cope with these deficiencies not in order to make the person "feel good" but in order to make the person feel "normal" -- or not to feel at all.

Persons diagnosed with co-occurring trauma and SUDs are at particular risk for being re-traumatized (van der Kolk, 2014). First, addiction in itself is highly traumatizing, exposing the person to life-threatening experiences and to severe disturbances. Second, both trauma and addiction adversely impact the person's ability to form safe and secure attachments (Siegal, 2010). Hence, the combined effect of CT with SUDs creates a snowball effect that leads to decreased functioning, reenactment, and an overall loss of a basic sense of safety and trust. This destructive cycle makes psychoactive substances catnip, and relapse a cure. Often times, this is the presentation of clients who are classified by professionals as problematic, defiant, resistant to treatment, or lacking motivation to change -- perceptions and views that further marginalize and re-traumatize survivors. TIC for social work practice with co-occurring trauma and SUDs deliberately avoids the use of marginalization and detrimental views of clients. Applying TIC requires assessing, diagnosing, perceiving, and approaching the most difficult client presentations through a thorough understanding of the impact of trauma and of CTT.

\section{Conclusions and Implications for Social Work}

Research findings concerning the relationship between CT and the subsequent underlying mechanisms contributing to the development of SUDs and to recovery from drug and alcohol addiction instigate a need for a comprehensive TIC model to guide clinical practices. An integrative TIC model is based on a sound theoretical foundation, cutting edge research findings, and clear targets for clinical intervention. Specifically, the relevancy of coping and resilience as curative factors to negate the impacts of CT hinder the development of SUDs, and are crucial in providing a sound base to TIC practices.

Treatment centers and programs for SUDs need to invest in training all personnel that are in direct contact with clients on the impact of trauma in order to apply a systematic trauma-informed therapeutic environment that is congruent with SAMHSA's (2015) guiding principles. Practicing in the field of addiction through the lens of TIC requires a shift in understanding the epidemiology of SUDs to include a consistent comprehension of the global impact of trauma, an ability to detect and determine the existence of trauma among diagnosed individuals, an integration of trauma-based knowledge and theory into policies and practices, and an active seeking to avoid re-traumatization of individuals (SAMHSA, 2015). Social workers need to be knowledgeable of the prevalence of CT among this clinical population and of the potential existence of CT history, especially among clients with challenging clinical presentations. Moreover, social workers need to deliver treatment interventions that are aimed at strengthening resilience and coping skills among clients. For example, integrating obtainable tasks and behavioral rewards that will mobilize clients to action such as: problem solving challenges; assuming responsibilities and roles within the residential treatment; and expanding communal connections by 
volunteering or attending self-help meetings. Social workers whose practice involves atrisk and traumatized populations need to integrate trauma-informed practices that are focused on creating opportunities to develop and enhance coping skills and resilience into prevention and early intervention programs for youth. Finally, it is recommended for social work educational institutions to adequately train BSW and MSW students - especially those entering the workforce in the field of addiction, whether in direct practice, administration, or policy -- in incorporating trauma-informed practices into prevention, assessment, and intervention in work with at-risk and clinical populations.

\section{References}

Armstrong, A. R., Galligan, R. F., \& Critchley, C. R. (2011). Emotional intelligence and psychological resilience to negative life events. Personality and Individual Differences, 51, 331-336. doi: https://doi.org/10.1016/j.paid.2011.03.025

Back, S. E., Killeen, T. K., Teer, A. P., Hartwell, E. E., Pederline, A., Beylotte, F., \& Cox, E. (2014). Substance use disorders and PTSD: An exploratory study of treatment preferences among military veterans. Addictive Behaviors, 39, 369-373. doi: https://doi.org/10.1016/j.addbeh.2013.09.017

Badenoch, B. (2008). Being a brain-wise therapist: A practical guide to interpersonal neurobiology. New York: W. W. Norton.

Banducci, A. N., Hoffman, E., Lejuez, C. W., \& Koenen, K. C. (2014a). The relationship between child abuse and negative outcomes among substance users:

Psychopathology, health, and comorbidities. Addictive Behaviors, 39, 1522-1527.

Banducci, A. N., Hoffman, E. M., Lejuez, C. W., Koenen, K. C. (2014b). The impact of childhood abuse on inpatient substance users: Specific links with risky sex, aggression, and emotion dysregulation. Child Abuse \& Neglect, 38, 928-938. doi: https://doi.org/10.1016/j.chiabu.2013.12.007

Beauvais, F., \& Oetting, E. R. (1999). Drug use, resilience, and the myth of the golden child. In M. D. Glantz \& J. L. Johnson (Eds.), Resilience and development: Positive life adaptations, (pp. 101-107). New York: Kluwer Academic/Plenum Publishers.

Becker-Blease, K. A., \& Freyd, J. J. (2005). Beyond PTSD: An evolving relationship between trauma theory and family violence research. Journal of Interpersonal Violence, 20(4), 403-411. doi: https://doi.org/10.1177/0886260504269485

Bloom, L. B., \& Farragher, F. (2011). Destroying sanctuary: The crisis in human service delivery system. New York: Oxford University Press.

Bombardier, C., Blake, K., Ehde, D., Gibbons, L., Moore, D., \& Kraft, G. (2004). Alcohol and drug abuse among persons with multiple sclerosis. Multiple Sclerosis, 10(1), 35-40. doi: https://doi.org/10.1191/1352458504ms989oa

Brown, S. M., Baker, C. N., \& Wilcox, P. (2012). Risking connection trauma training: A pathway toward trauma-informed care in child congregate care settings.

Psychological Trauma: Theory, Research, Practice, and Policy, 4(5), 507-515. doi: https://doi.org/10.1037/a0025269 
Brucker, D. (2007). Estimating the prevalence of substance use, abuse, and dependence among Social Security Disability benefit recipients. Journal of Disability Policy Studies, 18(3), 148-159. doi: https://doi.org/10.1177/10442073070180030301

Chou, C. C., Robb, J. L., Clay, M. C., \& Chronister, J. N. (2013). Social support as a mediator between internalized stigma and coping behaviors of individuals with substance abuse issues. Rehabilitation Research, Policy, and Education, 27(2), 104107. doi: https://doi.org/10.1891/2168-6653.27.2.104

Courtois, C. A. (2008). Complex trauma, complex reactions: Assessment and treatment. Psychological Trauma: Theory, Research, Practice, and Policy, S(1), 86-100. doi: https://doi.org/10.1037/1942-9681.S.1.86

Courtois, C. A., \& Ford, J. D. (2016). Treatment of complex trauma: A sequenced, relationship-based approach. NY: Guilford Press.

Covington, S. S. (2008). Women and addiction: A trauma informed approach. Journal of Psychoactive Drugs, 5, 377-385. doi: https://doi.org/10.1080/02791072.2008.10400665

Cowell, R. A., Cicchetti, D., Rogosch, F. A., \& Toth, S. L. (2015). Childhood maltreatment and its effect on neurocognitive functioning: Timing and chronicity matter. Development and Psychopathology, 27, 521-533. doi: https://doi.org/10.1017/S0954579415000139

Dickey, B., Azeni, H., Weiss, R., \& Sederer, L. (2000). Schizophrenia, substance-use disorders, and medical co-morbidity. Journal of Mental Health Policy and Economics, 3, 27-33. doi: https://doi.org/10.1002/1099-176X(200003)3:1<27::AIDMHP67>3.0.CO;2-P

Downey, L. A., Johnston, P. J., Hansen, K., Birney, J., \& Stough, C. (2010). Investigating the mediating effects of emotional intelligence and coping on problem behaviors in adolescents. Australian Journal of Psychology, 62(1), 20-29. doi: https://doi.org/10.1080/00049530903312873

Driessen, M., Schulte, S., Luedecke, C., Schaefer, I., Sutmann, F., Ohlmeier, M., ...the TRAUMAB-Study Group. (2008). Trauma and PTSD in patients with alcohol, drug, or dual dependence: A multi-center study. Alcoholism Clinical and Experimental Research, 32(3), 481-488. doi: https://doi.org/10.1111/j.1530-0277.2007.00591.x

Dube, S. R., Felitti, V. J., Dong, M., Chapman, D. P., Giles, W. H., \& Anda, R. F. (2003). Childhood abuse, neglect, and household dysfunction and the risk of illicit drug use: The Adverse Childhood Experiences Study. Pediatrics, 111(3), 564-572. doi: https://doi.org/10.1542/peds.111.3.564

Elwyn, L., \& Smith, C. (2013). Child maltreatment and adult substance abuse: The role of memory. Journal of Social Work Practice in the Addictions, 13, 269-294. doi: https://doi.org/10.1080/1533256X.2013.814483

Erozkan, A. (2013). Exploring the relationship between perceived emotional intelligence and coping skills of undergraduate students. International Journal of Human 
Sciences, 10(1), 1537-1549.

Farrugia, P. L., Mills, K. L., Barrett, E., Back, S. E., Teesson, M., Baker, A.,...Brady, K. T. (2011). Childhood trauma among individuals with co-morbid substance use and post- traumatic stress disorder. Mental Health and Substance Use, 4(4), 314-326. doi: https://doi.org/10.1080/17523281.2011.598462

Felitti, V. J., Anda, R. F., Nordenberg, D., Williamson, D. F., Spitz, A. M., Edwards, V.,... Marks, J. S. (1998). Relationship of childhood abuse and household dysfunction to many of the leading causes of death in adults: The Adverse Childhood Experiences (Ace) Study. American Journal of Preventive Medicine, 14(4), 245-258. doi: https://doi.org/10.1016/S0749-3797(98)00017-8

Finkelhor, D., Turner, H. A., Shattuck, A., \& Hamby, S. L. (2013). Violence, crime, and abuse exposure in a national sample of children and youth. Jama Pediatrics, 42, 614621. doi: https://doi.org/10.1001/jamapediatrics.2013.42

Finkelhor, D., Turner, H., Shattuck, A., Hamby, S., \& Kracke, K. (2015). Children's exposure to violence, crime, and abuse: An update. U.S. Department of Justice: Office of Justice Programs, Office of Juvenile Justice and Delinquency Prevention. Retrieved from https://www.ojjdp.gov/pubs/248547.pdf

Franken, I. H. A., Hendriks, V. M., Haffmans, J., \& van der Meer, C. W. (2003). Coping style of substance-abuse patients: Effects of anxiety and mood disorders on coping change. Journal of Clinical Psychology, 59(10), 1125-1132. doi: https://doi.org/10.1002/jclp.10205

Handley, E. D., Rogosch, F. A., Guild, D. J., \& Cicchetti, D. (2015). Neighborhood disadvantage and adolescent substance use disorder: The moderating role of maltreatment. Child Maltreatment, 20(3), 193-202. doi:https://doi.org/10.1177/1077559515584159

Harris, W. W., Lieberman, A. F., \& Marans, S. (2007). In the best interests of society. Journal of Child Psychology and Psychiatry, 48(3), 392-411. doi:https://doi.org/10.1111/j.1469-7610.2007.01732.x

Heffernan, K., Cloitre, M., Tardiff, K., Marzuk, P. M., Portera, L., \& Leon, A. C. (2000). Childhood trauma as a correlate of lifetime opiate use in psychiatric patients. Addictive Behaviors, 25, 797-803. doi: https://doi.org/10.1016/S03064603(00)00066-6

Henderson, N., \& Milstein, M. (1996). Resiliency in schools: Making it happen for students and educators. Thousand Oaks, CA: Corwin Press.

Herman, J. L. (1992). Trauma and recovery: The aftermath of violence - from domestic abuse to political terror. New York: Basic Books.

Jung, H., Herrenkohl, T. I., Klika, J. B., Olivia-Lee, J. O., \& Brown, E. C. (2014). Does child maltreatment predict adult crime? Reexamining the question in a prospective study of gender differences, education, and marital status. Journal of Interpersonal Violence, 30(13), 1-20. doi: https://doi.org/10.1177/0886260514552446 
Khantzian, E. J., \& Albanse, M. J. (2008). Understanding addiction as self-medication: Finding hope behind the pain. Lanham, MD: Rowman \& Littlefield.

Keyser-Marcus, L., Alvanzo, A., Rieckmann, T., Thacker, L., Sepulveda, A., Forcehimes,...Svikis, D. S. (2015). Trauma, gender, and mental health symptoms in individuals with substance use disorders. Journal of Interpersonal Violence, 30(1), 324. doi: https://doi.org/10.1177/0886260514532523

Kuper, L. E., Gallop, R., \& Greenfield, S. F. (2010). Changes in coping moderate substance abuse outcomes differentially across behavioral treatment modality. The American Journal on Addictions, 19, 543-549. doi: https://doi.org/10.1111/j.1521$\underline{0391.2010 .00074 . \mathrm{x}}$

Laplanche, J., \& Pontalis, J. B. (1973). The language of psycho-analysis. London: Hogarth Press.

Levendosky, A. A., \& Buttenheim, M. (2010). A multi-method treatment for child survivors of sexual abuse: An intervention informed by relational and trauma theories. Journal of Child Sexual Abuse, 9(2), 1-19. doi: https://doi.org/10.1300/J070v09n02_01

Levenson, J. S. (2014). Incorporating trauma-informed care into sex offender treatment. Journal of Sexual Aggression, 20(1), 9-22. doi: https://doi.org/10.1080/13552600.2013.861523

Levenson, J. (2015). Adverse childhood experiences and subsequent substance abuse in a sample of sexual offenders: Implications for treatment and prevention. Victims \& Offenders, 11(2), 199-224. doi: http://dx.doi.org/10.1080/15564886.2014.971478

Levenson, J. (2016). Adverse childhood experiences and subsequent substance abuse in a sample of sexual offenders: Implications for treatment and prevention. Victims \& Offenders, 11(2), 199-224. doi: https://doi.org/10.1080/15564886.2014.971478

Levenson, J., \& Grady M. (2016). Substance abuse, violence, and childhood adversity: Implications for trauma-informed social work practice. Journal of Social Practice in the Addictions, 16(1), 24-45. doi: https://doi.org/10.1080/1533256X.2016.1150853

Lewis, J. D. (2012). Towards a unified theory of trauma and its consequences. International Journal of Applied Psychoanalytic Studies, 9(4), 298-317. doi: https://doi.org/10.1002/aps.1305

Liu, Y., Wang, Z., \& Lü, W. (2013). Resilience and affect balance as mediators between trait emotional intelligence and life satisfaction. Personality and Individual Differences, 54, 850-855. doi: https://doi.org/10.1016/j.paid.2012.12.010

Lizeretti, N. P., Extremera, N., \& Rodriguez, A. (2012). Perceived emotional intelligence and clinical symptoms in mental disorders. Psychiatric Quest, 83, 407-418. doi: https://doi.org/10.1007/s11126-012-9211-9

Lyvers, S. L. M., \& Edward, M. S. (2008). Childhood sexual abuse and substance abuse in relation to depression and coping. Journal of Substance Use, 13(5), 349-360. doi: 
https://doi.org/10.1080/14659890802211077

Mészáros, J. (2010). Building blocks toward contemporary trauma theory: Ferenczi's paradigm shift. American Journal of Psychoanalysis, 70, 328-340. doi: https://doi.org/10.1057/ajp.2010.29

Mikolajczak, M., Nelis, D., Hansenne, M., \& Quoidbach, J. (2008). If you can regulate sadness, you can probably regulate shame: associations between trait emotional intelligence, emotion regulation and coping efficiency across discrete emotions. Personality and Individual Differences, 44, 1356-1368. doi: https://doi.org/10.1016/j.paid.2007.12.004

Montgomery, J. M., Schwean, V. L., Burt, J-A. G., Dyke, D. I., Thorne, K. J., Hindes, Y. L.,...Kohut, C. S. (2008). Emotional intelligence and resiliency in young adults with Asperger's disorder challenges and opportunities. Canadian Journal of School Psychology, 23(1), 70-93. doi: https://doi.org/10.1177/0829573508316594

National Center for Mental Health Promotion and Youth Violence Prevention. (2012). Childhood trauma and its effects on healthy development. Retrieved from http://sshs.promoteprevent.org/sites/default/files/trauma_brief_in_final.pdf

Nijenhuis, E. R. S., \& van der Hart, O. (2011). Dissociation in trauma: A new definition and comparison with previous formulations. Journal of Trauma \& Dissociation, 12(4), 416-445. DOI: 10.1080/15299732.2011.570592

O'Connor, M., \& Elklit, A. (2008). Attachment styles, traumatic events, and PTSD: A cross- sectional investigation of adult attachment and trauma. Journal of Attachment and Human Development, 10(1), 59-71. doi: https://doi.org/10.1080/14616730701868597

Oshri, A., \& Rogosch, F. A. (2013). Child maltreatment and mediating influences of childhood personality types on the development of adolescent psychopathology. Journal of Clinical Child \& Adolescent Psychology, 42(3), 287-301. doi: https://doi.org/10.1080/15374416.2012.715366

Perera, H. N., \& DiGiacomo, M. (2015). The role of trait emotional intelligence in academic performance during the university transition: An integrative model of mediation via social support, coping, and adjustment. Personality and Individual Differences, 83, 208-213. doi: https://doi.org/10.1016/j.paid.2015.04.001

Ringel, S., \& Brandell, J. R. (Eds.). (2012). Trauma: Contemporary directions, theory, practice, and research. Thousand Oaks, CA: Sage. doi: https://doi.org/10.4135/9781452230597

Roberts, A. C., Galassi, J. P., McDonald, K., \& Sachs, S. (2002). Re-conceptualizing substance abuse treatment in therapeutic communities: Resiliency theory and the role of social work practitioners. Journal of Social Work Practice in the Addictions, 2(2), 53-68. doi: https://doi.org/10.1300/J160v02n02 06

Ross, C. A. (2000). The trauma model: A solution to the problem of comorbidity in psychiatry. Richardson, TX: Manitou Communications. 
Saklofske, D. H., Austin, E. J., Galloway, J., \& Davidson, K. (2007). Individual difference correlates of health-related behaviors: preliminary evidence for links between emotional intelligence and coping. Personality and Individual Differences, 42, 491-502. doi: https://doi.org/10.1016/j.paid.2006.08.006

Salovey, P., \& Sluyter, D. J. (Eds.). (1997). Emotional development and emotional intelligence. New York: BasicBooks.

Schneider, T. R., Lyons, J. B., \& Khazon, S. (2013). Emotional intelligence and resilience. Personality and Individual Differences, 55, 909-914. doi:

https://doi.org/10.1016/j.paid.2013.07.460

Schutte, N. S., Malouff, J. M., \& Hine, D. W. (2011). The association of ability and trait emotional intelligence with alcohol problems. Addiction Research and Theory, 19(3), 260-265. doi: https://doi.org/10.3109/16066359.2010.512108

Shapiro, R. (2010). The trauma treatment handbook: Protocols across the spectrum. New York: W. W. Norton.

Shapiro, F. (2012). Getting past your past: Take control of your life with self-help techniques from EMDR therapy. NY: Rodale Books.

Siegal, D. J. (1999). The developing mind: How relationships and the brain interact to shape who we are. New York: Guilford.

Siegal, D. J. (2010). Mindsight: The new science of personal transformation. NY: Bantam Books.

Smyth, N. J., \& Wiechelt, S. A. (2005). Drug use, self-efficacy and coping skills among people with concurrent substance abuse and personality disorders: Implications for relapse prevention Journal of Social Work Practice in the Addictions, 5(4), 63-80. doi: https://doi.org/10.1300/J160v05n04_05

Substance Abuse and Mental Health Services Administration [SAMHSA]. (2012).Trauma definition. Part one: Defining trauma. Retrieved from http://www.samhsa.gov/traumajustice/traumadefinition/definition.aspx

SAMHSA. (2015). Trauma-Informed approach and trauma-specific interventions. Retrieved from: http://www.samhsa.gov/nctic/trauma-interventions

Suleiman, S. R. (2008). Judith Herman and contemporary trauma theory. Women's Studies Quarterly, 36, 1(2), 276-281. doi: https://doi.org/10.1353/wsq.0.0016

Tarren-Sweeney, M. (2013). An investigation of complex attachment- and trauma-related symptomatology among children in foster and kinship care. Child Psychiatry and Human Development, 44(6), 727- 741. doi: https://doi.org/10.1007/s10578-013-0366$\underline{\mathrm{x}}$

Toker, T., Tiryaki, H., Ozçürümez, G., \& Iskender, B. (2011). The relationship between traumatic childhood experiences and proclivities towards substance abuse, selfesteem and coping strategies. Turkish Journal of Psychiatry, 22(2), 83-92. 
Torchalla, I., Nosen, L., Rostam, H., \& Allen, P. (2012). Integrated treatment programs for individuals with concurrent substance use disorders and trauma experiences: A systematic review and meta-analysis. Journal of Substance Abuse Treatment, 42, 6577. doi: https://doi.org/10.1016/j.jsat.2011.09.001

Toth, S., Gravener-Davis, J. A., Guild, D. J., \& Cicchetti, D. (2013). Relational interventions for child maltreatment: Past, present, and future perspectives. Development and Psychopathology, 25, 1601-1617. doi: https://doi.org/10.1017/S0954579413000795

Turner, H. A., Finkelhor, D., \& Ormrod, R. (2010). Poly-victimization in a national sample of children and youth. American Journal of Preventive Medicine, 38(3), 323330. doi: https://doi.org/10.1016/j.amepre.2009.11.012

U.S. Department of Health and Human Services (HHS), Office of the Surgeon General, (2016). Facing Addiction in America: The Surgeon General's Report on Alcohol, Drugs, and Health. Washington, DC: HHS.

Valtonen, K., Sogren, M., \& Cameron-Padmore, J. (2006). Coping styles in persons recovering from substance abuse. British Journal of Social Work, 36, 57-73. doi: https://doi.org/10.1093/bjsw/bch247

van Dam, D. V., Ehring, T., Vedel, E., \& Emmelkamp, P. M. G. (2013). Trauma-focused treatment for posttraumatic stress disorder combined with CBT for severe substance use disorder: A randomized controlled trial. BMC Psychiatry, 13, 172-185.

Van der Kolk, B. A. (2014). The body keeps the score: Brain, mind, and body in the healing of trauma. New York: Penguin Group, LLC.

Van der Kolk, B., McFarlane, A. C., \& Weisaeth, L. (2006). Traumatic stress: The effects of overwhelming experiences on mind, body, and society. NY: Guilford.

Weiland, B. J., Nigg, J. T., Welsh, R. C., Yau, W-Y. W., Zubieta, J-K., Zucker, R. A., \& Heitzeg, M. M. (2012). Resiliency in adolescents at high risk for substance abuse: Flexible adaptation via subthalamic nucleus and linkage to drinking and drug use in early adulthood. Alcoholism: Clinical and Experimental Research, 36(8), 1355-1364. doi: https://doi.org/10.1111/j.1530-0277.2012.01741.x

Williams, W. I. (2006). Complex trauma: Approaches to theory and treatment. Journal of Loss and Trauma, 11, 321-335. doi: https://doi.org/10.1080/15325020600663078

Wu, N. S., Schairer, L. C., Dellor, E., \& Grella, C. (2010). Childhood trauma and health outcomes in adults with comorbid substance abuse and mental health disorders. Addictive Behaviors, 35, 68-71. doi: https://doi.org/10.1016/j.addbeh.2009.09.003

Zeidner, M., Kloda, I., \& Matthews, G. (2013). Does dyadic coping mediate the relationship between emotional intelligence (EI) and marital quality? Journal of Family Psychology, 27(5), 795-805. doi: https://doi.org/10.1037/a0034009

Zeidner, M., Matthews, G., \& Roberts, R. D. (2012). The emotional intelligence, health, and well-being nexus: What have we learned and what have we missed? Applied 
Psychology: Health and Well-Being, 4(1), 1-30. doi: https://doi.org/10.1111/j.17580854.2011.01062.x

Author note: Address correspondence to: Dr. Revital Goodman, Revital Goodman Psychotherapy, LLC, 9858 Glades Road \#D3-218, Boca Raton, FL 33434. 561-212-8446, revitalgoodman@gmail.com 